Superalloys 2012: $12^{\text {th }}$ International Symposium on Superalloys

\title{
RAFTING DURING HIGH TEMPERATURE DEFORMATION IN A SINGLE CRYSTAL SUPERALLOY: EXPERIMENTS AND MODELING
}

\author{
Bernard Fedelich $^{1}$, Alexander Epishin ${ }^{2}$, Thomas Link ${ }^{2}$, Hellmuth Klingelhöffer ${ }^{1}$, Georgia Künecke ${ }^{1}$, Pedro Dolabella Portella ${ }^{1}$ \\ ${ }^{1}$ Federal Institute for Materials Research and Testing (BAM), Department "Materials Engineering”, Berlin D12205, Germany \\ ${ }^{2}$ Technical University Berlin, Institute for Materials Science and Technologies, Berlin D10587, Germany
}

Keywords: Creep, Single Crystal, Rafting, Modeling, CMSX-4, Low-Cycle-Fatigue

\begin{abstract}
To characterize the kinetics of rafting, mechanical tests and microstructural investigations have been performed for the single crystal superalloy CMSX-4. The kinetics of microstructural degradation under constant load have been investigated in the temperature range $850-1100^{\circ} \mathrm{C}$ and for a large range of stress levels. An analytical model of the rafting kinetics has been proposed to represent the influence of temperature, stress and time on the microstructure degradation.

To predict the degradation effect of rafting on the mechanical behavior of single crystal superalloys and its kinetics during complex loadings, a specific viscoplastic constitutive model has been developed. The degree of rafting is incorporated in the model via the $\gamma$-channels width, which determines the Orowan stress. The rafting kinetics are assumed to be driven by the reduction of internal stresses represented by the macroscopic back-stress. The model has been calibrated for the temperatures $950^{\circ} \mathrm{C}$ and $1050^{\circ} \mathrm{C}$. Several validation tests have been simulated.
\end{abstract}

\section{Introduction}

Nickel-base superalloys are hardened by small intermetallic $\gamma^{\prime}$ precipitates of the $\mathrm{Ni}_{3} \mathrm{Al}$-type, which ensure excellent mechanical properties at high temperatures. The efficiency of this hardening strongly depends on the morphology and the size of the $\gamma / \gamma^{\prime}$ microstructure. After standard heat treatment, the $\gamma^{\prime}$-precipitates are roughly cuboidal and periodically arranged in the $\gamma$-matrix (Figure 1). During high temperature service in gas turbines or aero-engines the $\gamma / \gamma^{\prime}$-microstructure gradually degrades, i.e. it becomes rafted, coarsens (Figure 2) and eventually topologically inverts, so that the initial $\gamma$-matrix becomes the precipitate phase. As a consequence, the mechanical properties, like the tensile or the fatigue strength, significantly deteriorate [1-4]. Hence, this source of microstructural damage has to be considered for reliable prediction of the blade lifetime.

In a recently completed project, rafting kinetics have been extensively experimentally characterized in the widely used single-crystal superalloy CMSX-4 and implemented in a constitutive model for rafting prediction in components. In this paper, previously obtained test results $[3,5]$ have been extended to broader conditions including load free annealing, a higher temperature $\left(1100^{\circ} \mathrm{C}\right)$ and more complex loadings. In addition, an analytical model is presented that summarizes the microstructure measurements. The constitutive law previously proposed in [6] is extended to describe the case of arbitrary specimen orientations as well as rafting without external stress. Furthermore, creep in non $<001>$ smooth specimens and in notched specimens as well as cyclic stress relaxation tests have been simulated for validation.

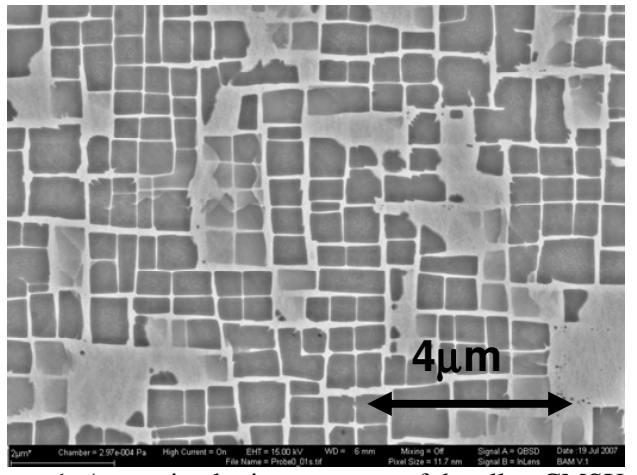

Figure 1. As received microstructure of the alloy CMSX-4.

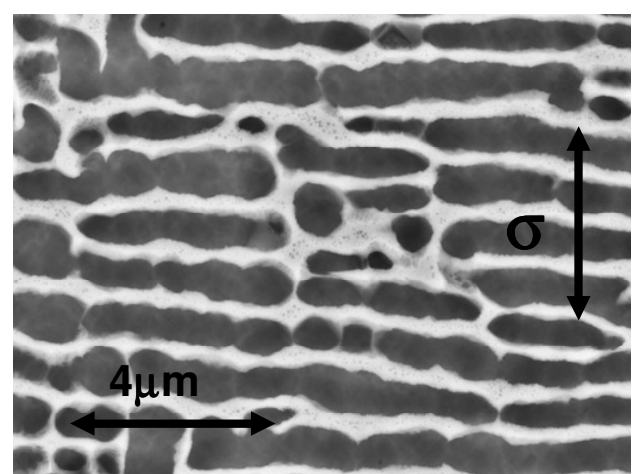

Figure 2. Microstructure after $375 \mathrm{~h}$ creep at $80 \mathrm{MPa}, 1050^{\circ} \mathrm{C}$.

\section{Summary of the Experimental Results}

\section{Experimental Conditions}

The kinetics of rafting has been investigated in the temperature range $850^{\circ} \mathrm{C}-1100^{\circ} \mathrm{C}$ and for a wide range of stress levels. To investigate the complete relevant parameter field (temperature $T$, stress $\sigma$, time $t$ ) a new procedure has been developed: repeated load annealing of Flat Wedge shaped (FW) specimens. The flat specimen surfaces allow observing the microstructure in a Scanning Electron Microscope (SEM) at intervals after removing the surface layer. Because of the wedge shape of the specimens, the stress changes linearly along the specimen axis, thus allowing investigating several (6) stress levels with a single specimen. Experimental details of the technique have been published in [5]. Moreover, at every test temperature specimens have been annealed without load. The degradation conditions are summarized in Table I. 
Table I. Degradation conditions of specimens of CMSX-4

\begin{tabular}{|c|c|c|c|c|c|c|}
\hline $\mathrm{T},{ }^{\circ} \mathrm{C}$ & $\begin{array}{c}\text { Stress range, } \\
\mathrm{MPa}\end{array}$ & \multicolumn{7}{|c|}{ Accumulated time t, h } \\
\hline 1100 & 0 & 6 & 30 & 60 & & \\
\hline 1100 & $72-120$ & 5 & 15 & 35 & 75 & \\
\hline 1050 & 0 & 14 & 70 & 140 & & \\
\hline 1050 & $56-94$ & 25 & 75 & 175 & 375 & 775 \\
\hline 1050 & $94-157$ & 10 & 30 & 70 & 150 & $243^{*}$ \\
\hline 1000 & 0 & 37 & 135 & 370 & & \\
\hline 1000 & $72-120$ & 50 & 150 & 350 & 750 & 1550 \\
\hline 1000 & $120-200$ & 10 & 30 & 70 & 150 & 310 \\
\hline 950 & 0 & 100 & 500 & 1000 & & \\
\hline 950 & $97-162$ & 100 & 300 & 700 & 1500 & 3100 \\
\hline 950 & $155-259$ & 100 & 300 & $572^{*}$ & & \\
\hline 900 & 0 & 360 & 1800 & 3600 & & \\
\hline 900 & $137-228$ & 200 & 600 & 1400 & 3000 & 6200 \\
\hline 900 & $228-381$ & 20 & 60 & 140 & 300 & $603^{*}$ \\
\hline 850 & 0 & 1300 & 6500 & 13000 & & \\
\hline 850 & $200-334$ & 500 & 1500 & 3500 & 7500 & \\
\hline 850 & $334-558$ & 20 & 60 & 140 & 300 & 620 \\
\hline
\end{tabular}

Unless otherwise specified, the degradation conditions correspond to uniaxial tension, the tensile axis being parallel to the [001] crystal direction. The microstructural degradation has been characterized by the increase of the width $w=w_{[001]}$ of the $\gamma$ channels perpendicular to the load axis. Additionally, the microstructure period $\lambda=\lambda_{[001]}=$ (precipitate width + channelwidth, see Figure 3), along the load axis [001] has been measured. In all cases, the results have been obtained by averaging a large number of individual measurements (see an example of the histogram of the measured channel widths in Figure 4).

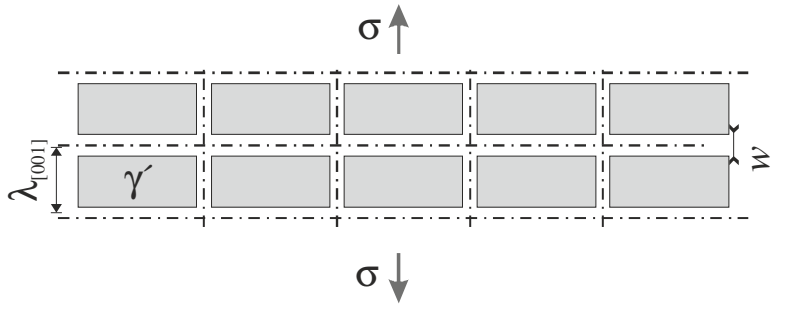

Figure 3. Idealized $\gamma / \gamma^{\prime}$-microstructure during uniaxial [001] tension creep.

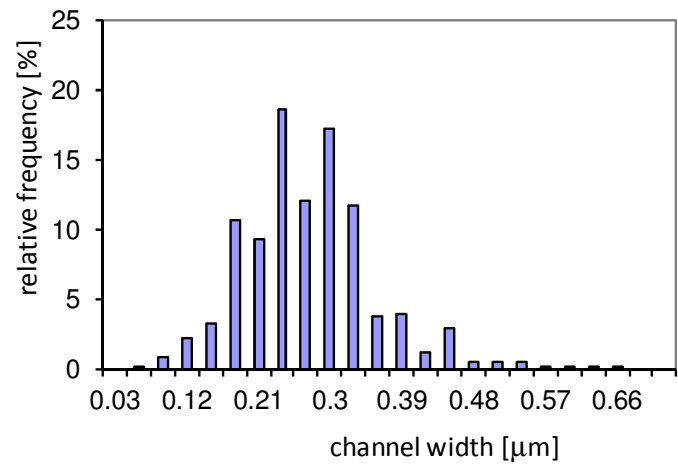

Figure 4. Measurements of the channel widths after $375 \mathrm{~h}$ creep time at $1050^{\circ} \mathrm{C}$ at the stress level $80 \mathrm{MPa}$. Number of individual measurements: 602 .

As expected, the kinetics of degradation strongly depend on the temperature and moderately on the stress level. Rafting is also observed without external stresses. As shown in [7], the magnitude of the internal stresses induced by the dendritic heterogeneities is sufficient to trigger the microstructural degradation even without external stresses. As an example, Figures 5 and 6 present the evolution of the channel width for several stress level at $850^{\circ} \mathrm{C}$ and $1100^{\circ} \mathrm{C}$. While at $1100^{\circ} \mathrm{C}$ the rafting rate is initially maximal and then progressively decreases, at $850^{\circ} \mathrm{C}$ an incubation time can be observed.

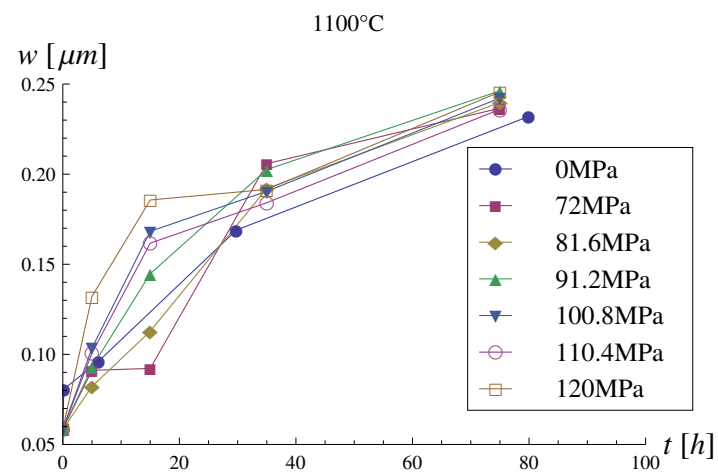

Figure 5. Channel width during creep at $1100^{\circ} \mathrm{C}$.

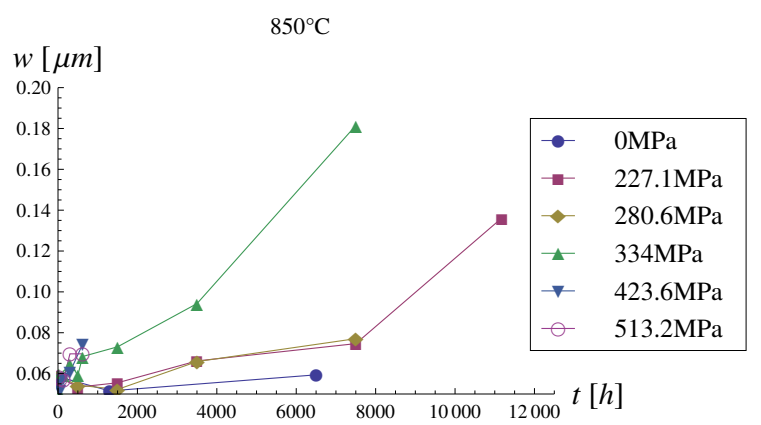

Figure 6. Channel width during creep at $850^{\circ} \mathrm{C}$. 
Analytical Representation of the SEM Measurements

Periodicity Width. The analytical representation is based on the assumption that the channel width $w(t)$ increases during creep due to the combination of two phenomena that take place in parallel (see Figure 7):

- homothetic growth of the $\gamma^{\prime}$-precipitates, also called isotropic coarsening,

- coalescence of adjacent precipitates, also called rafting.

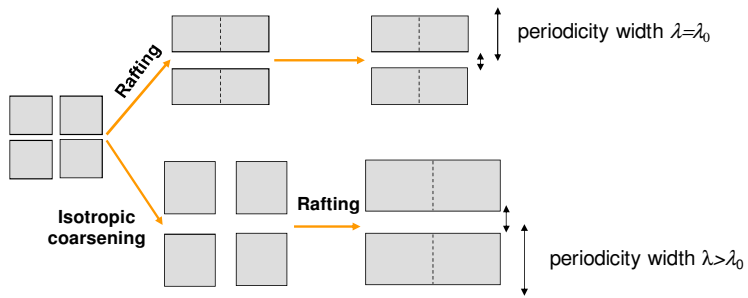

Figure 7. Schematic representation of microstructural degradation during tensile creep.

Consequently, $w(t)$ varies between two time-dependent limits $w_{\text {cube }}(t)$ and $w_{\text {raft }}(t)$, which correspond to either the ideal cube morphology or infinite plates respectively growing under isotropic coarsening. For a given volume fraction of the $\gamma^{\prime}$-phase $f_{\gamma^{\prime}}$, these limits are given by

$$
w_{\text {cube }}=\left(1-\sqrt[3]{f_{\gamma^{\prime}}}\right) \lambda,
$$

for a cubic microstructure and

$$
w_{\text {raft }}=\left(1-f_{\gamma^{\prime}}\right) \lambda,
$$

for infinite plates perpendicular to the [001] stress axis. The degree of isotropic coarsening is described by the periodicity width $\lambda(t)$ along [001] and the degree of rafting is defined by the dimensionless variable

$$
\xi=\frac{w-w_{\text {cube }}}{w_{\text {raft }}-w_{\text {cube }}}, \quad 0 \leq \xi \leq 1
$$

ranging from 0 for $\gamma^{\prime}$-cubes up to 1 for infinite $\gamma^{\prime}$-plates.

For all temperatures it has been found that the increase of the periodicity width is independent of the stress level and can be represented by the following analytical model (coefficient of determination $R^{2}=0.994$ ):

$$
\lambda_{\text {[001] }}=\lambda_{\text {[001] }}^{0}\left[1+D_{0} \exp \left(-\frac{Q_{\lambda}}{R T}\right) t\right]^{a}
$$

where $R$ denotes the gas constant and with the values $\lambda_{\text {[001] }}^{0}=0.709 \mu \mathrm{m}, a=0.0745, D_{0}=5.2010^{9} \mathrm{~s}^{-1}$,

$Q_{\lambda}=354 \mathrm{~kJ} \mathrm{~mol}^{-1}$. Figures 8 and 9 show a comparison between the analytical model and SEM measurements at $850^{\circ} \mathrm{C}$ and $1100^{\circ} \mathrm{C}$.

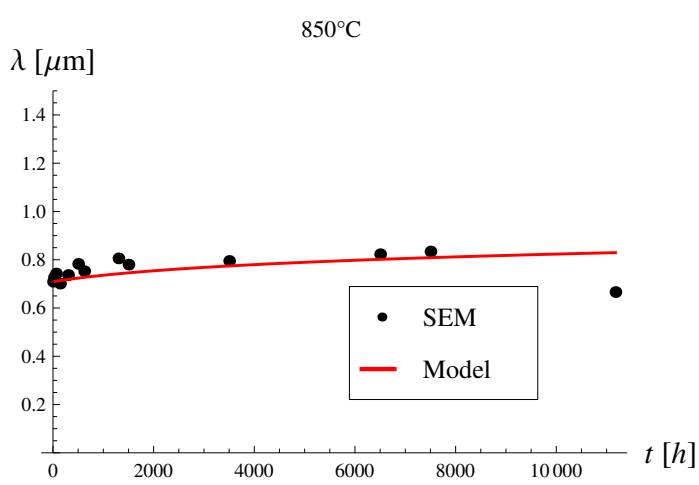

Figure 8 . Increase of the periodicity width at $850^{\circ} \mathrm{C}$

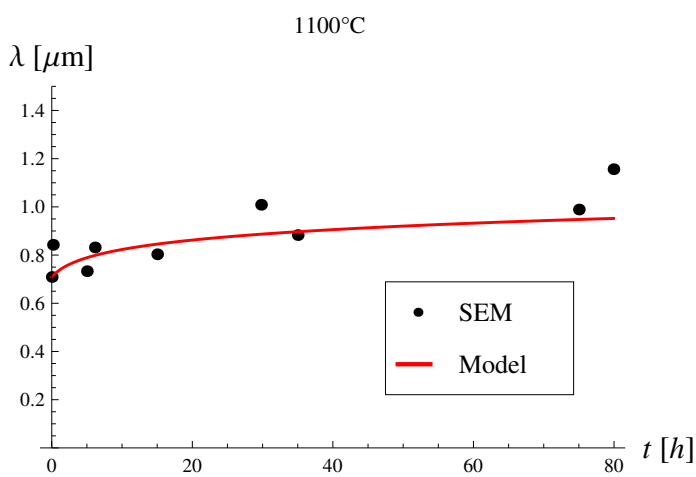

Figure 9 . Increase of the periodicity width at $1100^{\circ} \mathrm{C}$.

Figure 10 demonstrates the dependence of the periodicity width within the parameter $(t, T)$ range.

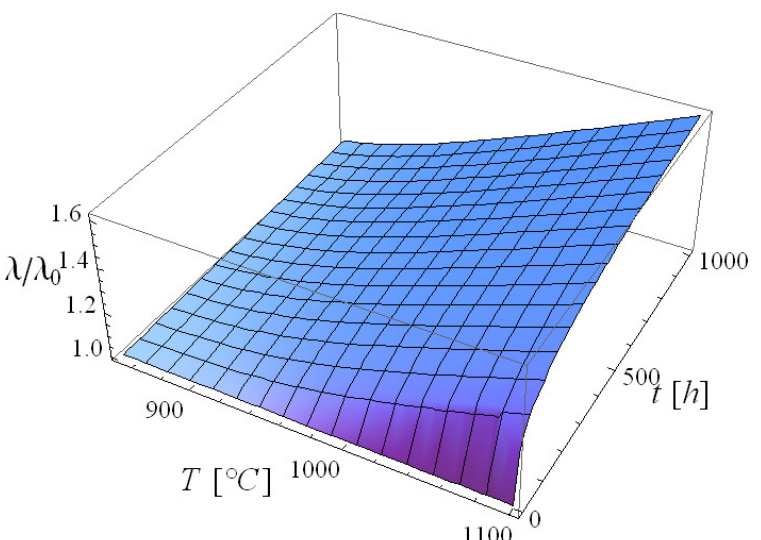

Figure 10. Increase of the periodicity width with time and temperature.

Note that the volume fraction of the $\gamma^{\prime}$ phase is needed at the testing temperature. For temperatures higher than $850^{\circ} \mathrm{C}$, the decrease of $f_{\gamma^{\prime}}(T)$ is given by 


$$
f_{\gamma^{\prime}}(T)=f_{\gamma^{\prime}}(R T)\left\{1-\left(\frac{T-T_{E}}{T_{S}-T_{E}}\right)^{n}\right\}
$$

with $T_{E}=1123 \mathrm{~K}, T_{S}=1553 \mathrm{~K}$ and $n=2.103$ [8]. This formula gives results very close to that of Roebuck et al. [9] (see Figure $11)$.

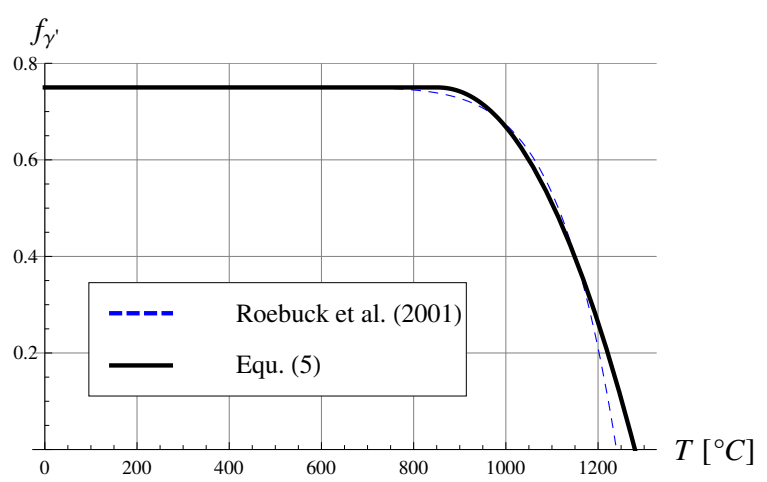

Figure 11. $\gamma^{\prime}$ volume fraction of the alloy CMSX-4.

SEM measurements of the initial microstructure at RT provided the average value $w_{\text {cube }}^{0}=0.058 \mu m$ for the channel width, $c^{0}=0.573 \mu \mathrm{m}$ for the precipitate size and $\lambda^{0}=0.709 \mu \mathrm{m}$ for the microstructure period. From these direct measurements follows an estimate of the $\gamma^{\prime}$ volume fraction $f_{\gamma^{\prime}}=\left(c^{0} /\left(c^{0}+w^{0}\right)\right)^{3}=0.748$. This value is close to the value obtained in [9] by resistivity measurements $f_{\gamma^{\prime}}=0.75$ and has been be used in the following.

Channel Width. Similarly to equ. (4), the degree of rafting progress can be described by the following analytical model (coefficient of determination $R^{2}=0.971$ ):

$$
\xi=1-\exp \left[-A_{0} \exp \left(-\frac{Q_{\xi}}{R T}\right)\left(1+\frac{\sigma}{\sigma_{0}}\right)^{p} t\right],
$$

with the values $A_{0}=1.1610^{10} \mathrm{~s}^{-1}, p=9.83, Q_{\xi}=405 \mathrm{~kJ} \mathrm{~mol}^{-1}$ and $\sigma_{0}=955 \mathrm{MPa}$. Accordingly, rafting occurs without external stresses. Because in most creep tests $\sigma<<\sigma_{0}$, the rafting degree $\xi$ exhibits only a moderate stress dependence.

Figures 12 to 16 show a comparison between the analytical model and SEM measurements for several conditions. On account of the large scatter of the measurements, the model provides a fairly good representation of the functional dependence of the channel width within the parameter range $(t, T, \sigma)$. The lower dashed curves indicate the lower limit $w_{\text {cube }}(t)$ in which the $\gamma^{\prime}$ precipitates remain cubes and the upper dashed curves the upper limit $w_{\text {raft }}(t)$ in which the rafts (infinite plates) exist from the beginning. The black curves (analytical model) show the transition from cubes into rafts.

For a comparable stress level, Figures 12 to 15 demonstrate the strong dependence of rafting kinetics on the temperature. At sufficiently high temperature, rafting without external stress becomes significant (Figure 16).

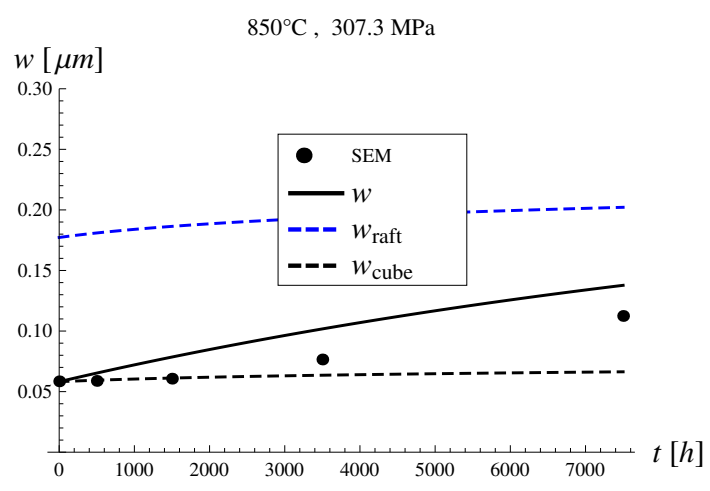

Figure 12. Channel widening at $850^{\circ} \mathrm{C}$ and $307.3 \mathrm{MPa}$.

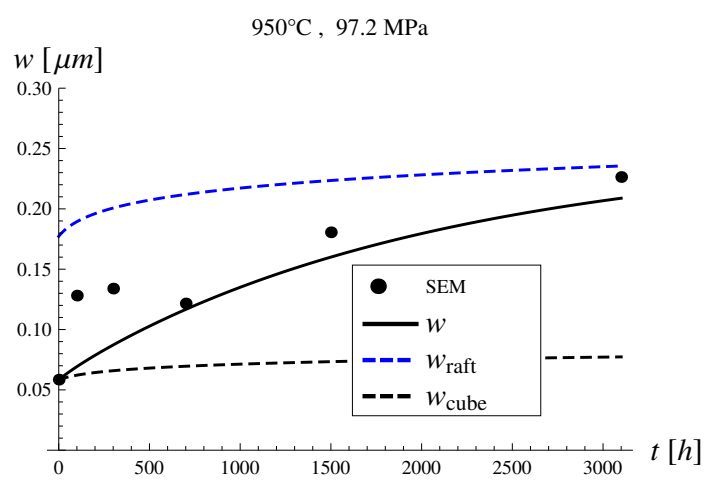

Figure 13. Channel widening at $950^{\circ} \mathrm{C}$ and $97.2 \mathrm{MPa}$.

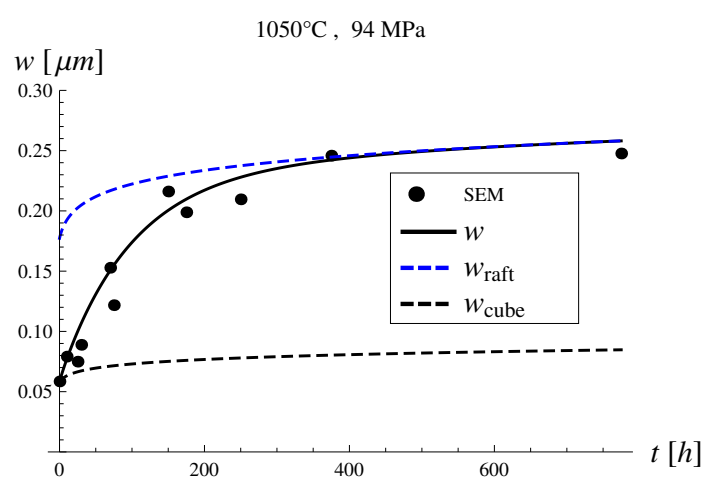

Figure 14: Channel widening at $1050^{\circ} \mathrm{C}$ and $94 \mathrm{MPa}$. 


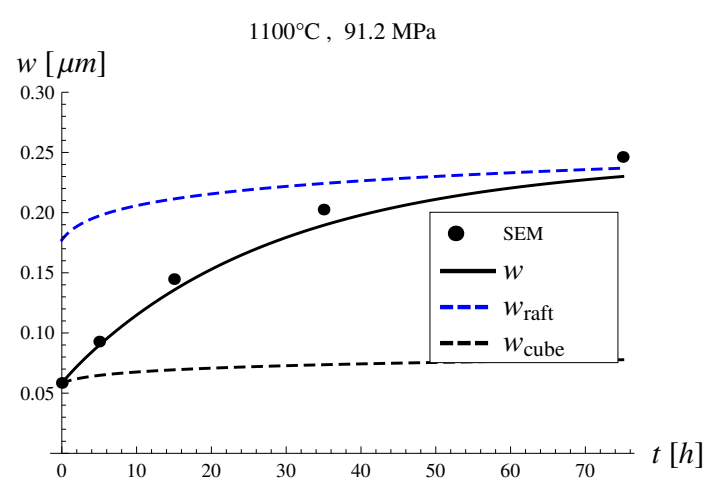

Figure 15. Channel widening at $1100^{\circ} \mathrm{C}$ and $91 . \mathrm{MPa}$.

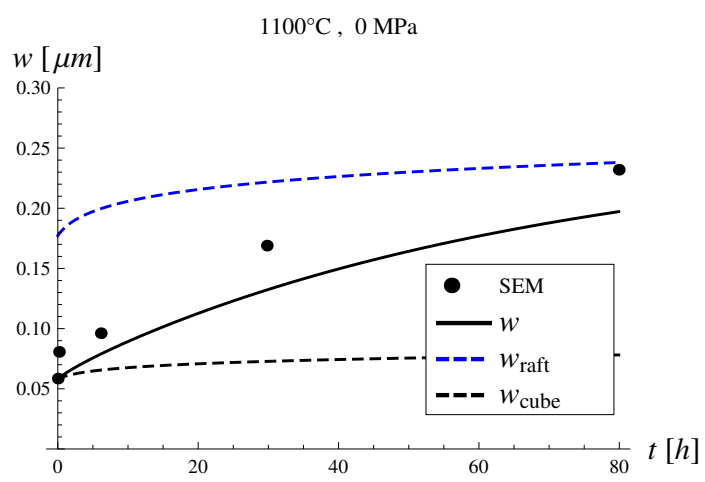

Figure 16. Channel widening under load-free annealing at $1100^{\circ} \mathrm{C}$.

Finally, Figure 17 demonstrates the dependence of channel widening on stress and time at $950^{\circ} \mathrm{C}$ as predicted by the model.

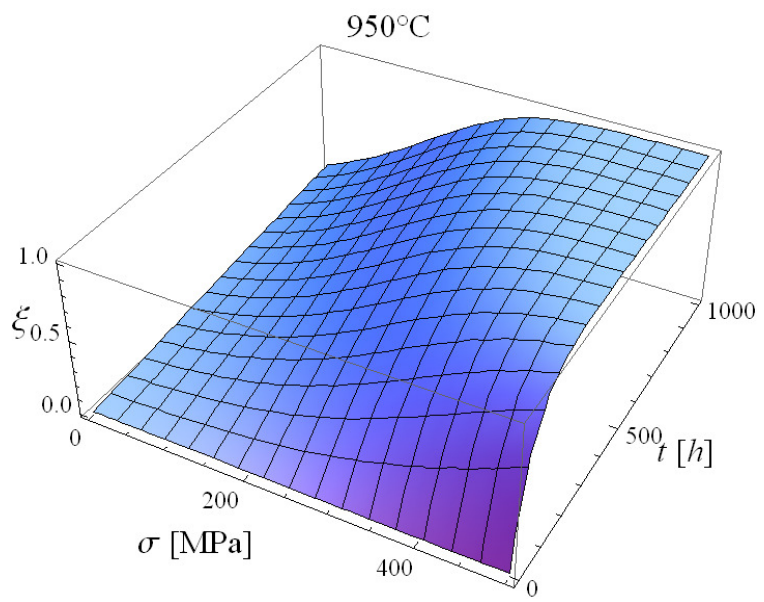

Figure 17. Stress and time dependence of channel widening at $950^{\circ} \mathrm{C}$.

\section{Constitutive Modeling}

\section{$\underline{\text { Model Presentation }}$}

The model presented in this part is a phenomenological viscoplastic model for single crystals, which possesses a relatively low number of internal variables and is thus suitable for structural analysis of large components. The model can be considered as a further development of the framework proposed by Méric et al. in [10]. The model has been designed for arbitrary oriented crystals, for monotonous and cyclic processes and for short term as well as long term deformation processes.

A previous version of the model has been presented in [6]. The formulation has been extended to account for cubic slip and rafting without external stress. For completeness, all model equations are summarized in the following sub-sections. Briefly, the framework of [10] has been modified to address the following effects:

- The high temperature deformation processes are essential thermally activated. This is accounted for by systematically using Arrhenius like laws.

- Octahedral glide starts in the channels and is mainly controlled by the channel width.

- Cubic glide is due to cross-slip of $a / 2<01 \overline{1}>$ dislocations, which are themselves generated during octahedral slip.

- Kinematic hardening is mainly due to the deposition of dislocation segments on the $\gamma / \gamma^{\prime}$ interfaces and the local stresses that they induce. Hence, the back stress induced by one slip system operates on all systems.

- During long term deformation processes, the microstructure evolves, which leads to a broadening of the matrix channels. As a consequence, the strength of the alloy is reduced.

In view of the small strain range considered throughout the project, the usual additive strain decomposition

$$
\boldsymbol{\varepsilon}=\boldsymbol{\varepsilon}^{e}+\boldsymbol{\varepsilon}^{p}
$$

applies. The Hooke's law reads

$$
\boldsymbol{\sigma}=\mathbf{C}: \boldsymbol{\varepsilon}^{e},
$$

with the cubic stiffness tensor $\mathbf{C}$. The octahedral and the cubic slip systems will be throughout denoted with the superscript $o$, respectively $c$. In particular, the plastic flow can be written in the form

$$
\begin{aligned}
\dot{\boldsymbol{\varepsilon}}^{p} & =\frac{1}{2} \sum_{g=1}^{12}\left(\mathbf{n}_{g}^{o} \otimes \mathbf{m}_{g}^{o}+\mathbf{m}_{g}^{o} \otimes \mathbf{n}_{g}^{o}\right) \dot{\gamma}_{g}^{o} \\
& +\frac{1}{2} \sum_{g=1}^{6}\left(\mathbf{n}_{g}^{c} \otimes \mathbf{m}_{g}^{c}+\mathbf{m}_{g}^{c} \otimes \mathbf{n}_{g}^{c}\right) \dot{\gamma}_{g}^{c},
\end{aligned}
$$

where the unit vectors $\mathbf{m}_{g}^{o}, \mathbf{m}_{g}^{c}$ denote the slip direction and $\mathbf{n}_{g}^{o}, \mathbf{n}_{g}^{c}$ the normal to the slip plane. The resolved shear stresses on both families of slip systems are defined as

$$
\tau_{g}^{o}=\mathbf{m}_{g}^{o} \cdot \boldsymbol{\sigma} \cdot \mathbf{n}_{g}^{o}, \quad \tau_{g}^{c}=\mathbf{m}_{g}^{c} \cdot \boldsymbol{\sigma} \cdot \mathbf{n}_{g}^{c} .
$$

Octahedral Slip. The dislocations can only expand in the narrow $\gamma$ channels when the local resolved shear stress of a slip system exceeds the Orowan stress 


$$
\tau^{\text {Orowan }}=\alpha \frac{\mu b}{w},
$$

where $w$ denotes the current channel width, $\mu$ the shear modulus and $b$ the magnitude of the Burgers vector. As explained in [6], the pre-factor $\alpha$ has to be treated as an adjustable parameter. The flow rule has the form

$$
\begin{aligned}
& \dot{\gamma}_{g}^{o}=\dot{v}_{g}^{o} \operatorname{sign}\left(\tau_{g}^{o}-x_{g}^{o}\right), \\
& \operatorname{sign}(x)=1 \text { if } x \geq 0 \text { and } \operatorname{sign}(x)=-1 \text { if } x<0, \\
& \dot{v}_{g}^{o}=\rho_{g}^{o} \sinh \left[\frac{V_{f}^{o}}{k T} \hat{\tau}_{g}\left\{1-\left[1+\left(\frac{\hat{\tau}_{g}}{\tau^{\text {Orowan }}}\right)^{s}\right]^{-1 / s}\right\},\right.
\end{aligned}
$$

where $V_{f}^{o}$ is the activation volume for dislocation glide, $\hat{\tau}_{g}=\left|\tau_{g}^{o}-x_{g}^{o}\right|$, and $x_{g}^{o}$ is the back stress on the slip system $g$. The

Boltzmann constant is denoted by $k$ and $T$ is the absolute temperature. The quantity $\rho_{g}^{o}$ is proportional to the dislocation density of the corresponding system. We assume for it a law with saturation, i.e.

$$
\rho_{g}^{o}=\rho_{0}^{o}+\left(\rho_{\infty}^{o}-\rho_{0}^{o}\right)\left[1-\exp \left(-v_{g}^{o} / b^{o}\right)\right]
$$

The degree of smoothness of the elastic-plastic transition is controlled by the exponent $s$. The limit $s \rightarrow \infty$ corresponds to a sharp yield threshold at $\hat{\tau}_{g}=\tau^{\text {Orowan }}$, while for low values of $s$ plastic flow becomes possible at $\hat{\tau}_{g}<\tau^{\text {Orowan }}$.

Kinematic hardening is described by a tensor variable denoted by $\mathbf{X}^{o}$, in accordance with the calculations of the internal stresses in the $\gamma / \gamma^{\prime}$ compound performed in [11]. The back-stresses at the level of the slip system are then obtained by

$$
x_{g}^{o}=\mathbf{n}_{g}^{o} \cdot \mathbf{X}^{o} \cdot \mathbf{m}_{g}^{o}, \quad \mathbf{X}^{o}=c^{o} \boldsymbol{\alpha}^{o},
$$

where $c^{o}$ is a numerical constant homogeneous to a stiffness. Conversely, the contribution $\dot{\alpha}_{g}^{o}$ of each slip system to the evolution of $\boldsymbol{\alpha}^{o}$ is assumed to take the form

$$
\dot{\alpha}_{g}^{o}=\dot{\gamma}_{g}^{o}-\dot{v}_{g}^{o} g^{o}\left(x_{g}^{o}\right)-h^{o}\left(x_{g}^{o}\right) \text {. }
$$

The second and the third terms on the right hand side of equ. (15) correspond to dynamic and static recovery, respectively. Here also, thermally activated processes are assumed, i.e.

$$
g^{o}(x)=d^{o} \sinh \left[\frac{V_{d}^{o} x}{k T}\right], \quad h^{o}(x)=h^{o} \sinh \left[\frac{V_{s}^{o} x}{k T}\right],
$$

where $d^{o}, h^{o}, V_{d}^{o}$ and $V_{s}^{o}$ are adjustable model parameters. The evolution of the tensorial internal strain $\alpha^{o}$ finally results from the contributions of all slip systems

$$
\dot{\boldsymbol{\alpha}}^{o}=\frac{1}{2} \sum_{g=1}^{12}\left(\mathbf{n}_{g}^{o} \otimes \mathbf{m}_{g}^{o}+\mathbf{m}_{g}^{o} \otimes \mathbf{n}_{g}^{o}\right) \dot{\alpha}_{g}^{o} .
$$

Cubic Slip. The plastic shear rate for the cubic systems is supposed to follow a similar thermal activation law of the form

$$
\dot{\gamma}_{g}^{c}=\dot{v}_{g}^{c} \operatorname{sign}\left(\tau_{g}^{c}-x_{g}^{c}\right), \quad \dot{v}_{g}^{c}=\rho_{g}^{c} \sinh \left[\frac{V_{f}^{c}\left\langle\left|\tau_{g}^{c}-x_{g}^{c}\right|-r_{0}^{c}\right\rangle}{k T}\right] \text {. }
$$

In contrast to the shear rate of the octahedral systems, it was found that the use of an exponent to control the degree of smoothness of the elastic-plastic transition (compare with equ. (12)) didn't improve the description of the experimental data. Thus, to limit the number of adjustable parameters, the exponent was drop in equ. (18).

Note that the existence of cubic slip as an independent mechanism is quite controversial [12]. According to observations on $<111>$ specimens [13], cubic slip arises from alternating cross-slip of $a / 2<01 \overline{1}>$ dislocations. The present work follows this line. Accordingly, the dislocation density for cubic slip is driven by octahedral slip. This is taken into account as follows for the cubic system $g$

$$
\begin{aligned}
& \rho_{g}^{c}=\rho_{0}^{c}+\left(\rho_{\infty}^{c}-\rho_{0}^{c}\right) \sum_{i=1}^{12} \varepsilon_{g i}\left[1-\exp \left(-v_{i}^{o} / b^{c}\right)\right], \\
& \varepsilon_{g i}=1 \text { if } g \text { and } i \text { have the same Burgers vector, } \\
& \varepsilon_{g i}=0 \text { if } g \text { and } i \text { have a different Burgers vector. }
\end{aligned}
$$

In accordance, $v_{i}^{o}$ is the cumulated slip on the octahedral system $i$. In a similar way to octahedral systems, the internal stresses generated by cubic slip are also represented by a tensorial backstress, i.e.

$$
x_{g}^{c}=\mathbf{n}_{g}^{c} \cdot \mathbf{X}^{c} \cdot \mathbf{m}_{g}^{c},
$$

The evolution of the internal stress $\mathbf{X}^{c}$ is assumed to follow the same laws as for octahedral systems, i.e.

$$
\begin{aligned}
& \mathbf{X}^{c}=c^{c} \boldsymbol{\alpha}^{c}, \\
& \dot{\alpha}_{g}^{c}=\dot{\boldsymbol{\gamma}}_{g}^{c}-\dot{\mathbf{v}}_{g}^{c} g^{c}\left(x_{g}^{c}\right)-h^{o}\left(x_{g}^{c}\right), \\
& \dot{\boldsymbol{\alpha}}^{c}=\frac{1}{2} \sum_{g=1}^{12}\left(\mathbf{n}_{g}^{c} \otimes \mathbf{m}_{g}^{c}+\mathbf{m}_{g}^{c} \otimes \mathbf{n}_{g}^{c}\right) \dot{\boldsymbol{\alpha}}_{g}^{c},
\end{aligned}
$$

where $c^{c}$ is a numerical constant homogeneous to a stiffness. The second and the third terms on the right hand side of $(21)_{2}$ correspond to dynamic and static recovery, respectively. Again, thermal activated processes are assumed, i.e.

$$
g^{c}(x)=d^{c} \sinh \left[\frac{V_{d}^{c} x}{k T}\right], \quad h^{c}(x)=h^{c} \sinh \left[\frac{V_{s}^{c} x}{k T}\right],
$$

where $d^{c}, h^{c}, V_{d}^{c}$ and $V_{s}^{c}$ are adjustable model parameters.

Microstructural Degradation. The present model assumes a recoverable energy (stored elastic energy) of the form

$$
\psi\left(\boldsymbol{\varepsilon}^{e}, \boldsymbol{\alpha}^{o}, \boldsymbol{\alpha}^{c}, \xi\right)=\underbrace{\frac{1}{2} \boldsymbol{\varepsilon}^{e}: \mathbf{C}: \boldsymbol{\varepsilon}^{e}}_{\text {macroscopic elastic energy }}+\underbrace{\psi^{\text {micro }}\left(\boldsymbol{\alpha}^{o}, \boldsymbol{\alpha}^{c}, \xi\right)}_{\text {microscopic elastic energy }},
$$

where the microscopic part is decomposed as the sum of contributions of the dislocation and the dendritic stresses

$$
\psi^{\text {micro }}\left(\boldsymbol{\alpha}^{o}, \boldsymbol{\alpha}^{c}, \boldsymbol{\xi}\right)=\underbrace{\frac{1}{2} c^{o}(\xi) \boldsymbol{\alpha}^{o}: \boldsymbol{\alpha}^{o}}_{\text {octahedral slip systems }}+\underbrace{\frac{1}{2} c^{c} \boldsymbol{\alpha}^{c}: \boldsymbol{\alpha}^{c}}_{\text {cubic slip systems }}+\underbrace{\frac{1}{2} \kappa(\xi) \delta_{u}{ }^{2}}_{\text {dendritic stresses }},
$$

where $\delta_{u}$ denotes the unconstrained lattice misfit.

The analysis of a microstructural model for the $\gamma / \gamma^{\prime}$ composit (see [14]) demonstrated that the main contribution to the driving force for rafting is the relaxation of the internal energy $\psi^{\text {micro }}$ with $\xi$. This effect can be described by assuming that $c^{o}=c^{o}(\xi)$ and $\kappa(\xi)$ are decreasing functions of $\xi$. It is not expected that the 
cubic slip systems will contribute to the driving force for rafting. Hence, $c^{c}$ is assumed to remain constant. Specifically, we take

$$
c^{o}(\xi)=c_{0}\left(1-c_{1} \xi\right), \quad \kappa(\xi)=\kappa_{0}\left(1-\kappa_{1} \xi\right) .
$$

The driving force for rafting is then

$$
X=-\frac{\partial \psi}{\partial \xi}=\frac{1}{2} c_{0} c_{1} \boldsymbol{\alpha}^{o}: \boldsymbol{\alpha}^{o}+\frac{1}{2} \kappa_{0} \kappa_{1} \delta_{u}^{2} .
$$

An evolution equation for the degree of rafting advancement with saturation for $\xi \rightarrow 1$ is postulated as a power law of the driving force

$$
\dot{\xi}=(1-\xi) f^{r a f t} X^{n},
$$

where $f^{\text {raft }}$ and $n$ are two model parameters. In summary, the effect of microstructural degradation is twofold:

- It reduces the Orowan stress by increasing the channel width according to $w=w_{\text {cube }}+\xi\left(w_{\text {raft }}-w_{\text {cube }}\right)$, where $w_{c u b e}$ and $w_{\text {raft }}$ also grow due to isotropic coarsening following equ. (1) and (2),

- It reduces the back stress, given by equ. (14) and (25).

\section{Model calibration}

The present model has been calibrated for the temperatures $950^{\circ} \mathrm{C}$ and $1050^{\circ} \mathrm{C}$. The test data included tests with [001] and [111] specimens, strain controlled tension tests, Low Cycle Fatigue (LCF) tests without and with relaxation as well as creep tests. The values of the adjustable model parameters have been identified by fitting the tests results in a three step procedure:

1. The parameters $\alpha, \rho_{0}^{o}, \rho_{\infty}^{o}, s, V_{f}^{o}, b^{o}, c^{o}, V_{d}^{o}, d^{o}$ that control the short term behavior, i.e. fast deformation processes that leave the $\gamma / \gamma^{\prime}$-morphology unchanged, have been identified with the results of tensile tests and with the first cycles of strain controlled cyclic tests with and without dwell.

2. The evolution of the channel width and periodicity width has been imposed as function of time and external stress according to equ. (1-6). The parameters of the static recovery $h^{o}, V_{s}^{o}$ have been then identified by using the creep results.

3. The parameters of the evolution equations (26)-(27) for the degree of rafting, $c_{0} c_{1}, \kappa_{0} \kappa_{1}, f^{\text {raft }}$ and $n$, have been fitted with SEM measurements of the channel widths.

The steps 1-3 have been first carried out to identify the parameters of the octahedral systems. Subsequently the steps 1 and 2 have been performed for the parameters of the cubic systems. Some examples of the graphic comparisons between the simulations and test results are presented in the following figures. The Figures 18 to 21 show that the short term behaviour is correctly represented.

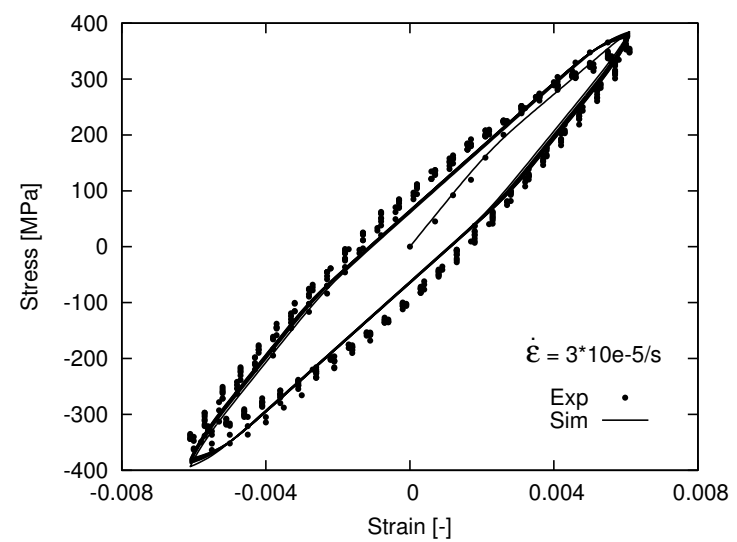

Figure 18. Simulation of a strain controlled cyclic test at $1050^{\circ} \mathrm{C}$ (specimen orientation $=[001])$.

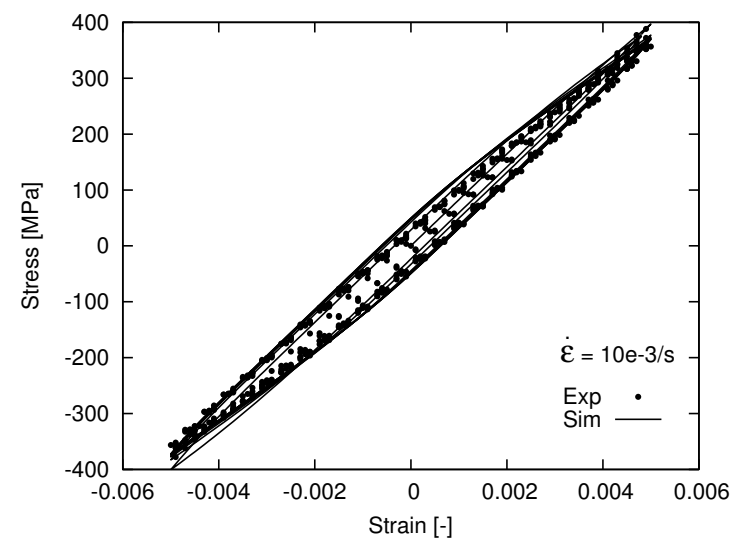

Figure 19. Simulation of a strain controlled cyclic test at $1050{ }^{\circ} \mathrm{C}$ (specimen orientation $=[001])$.

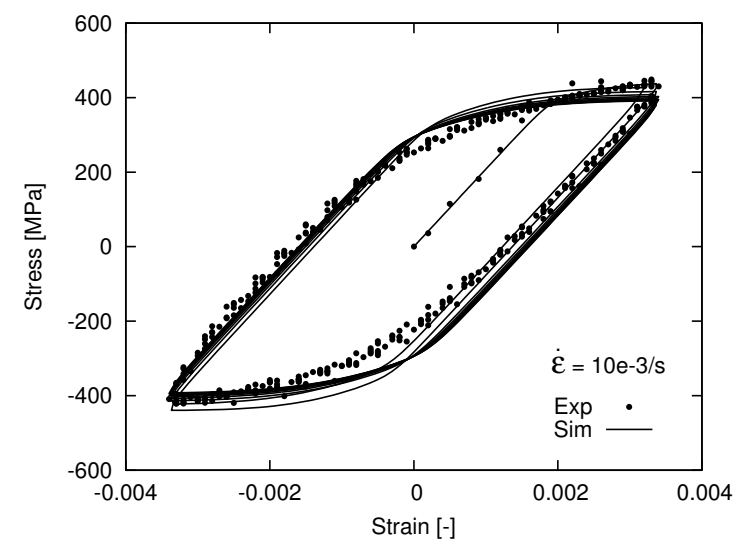

Figure 20. Simulation of a strain controlled cyclic test at $1050^{\circ} \mathrm{C}$ $($ specimen orientation $=[111])$. 


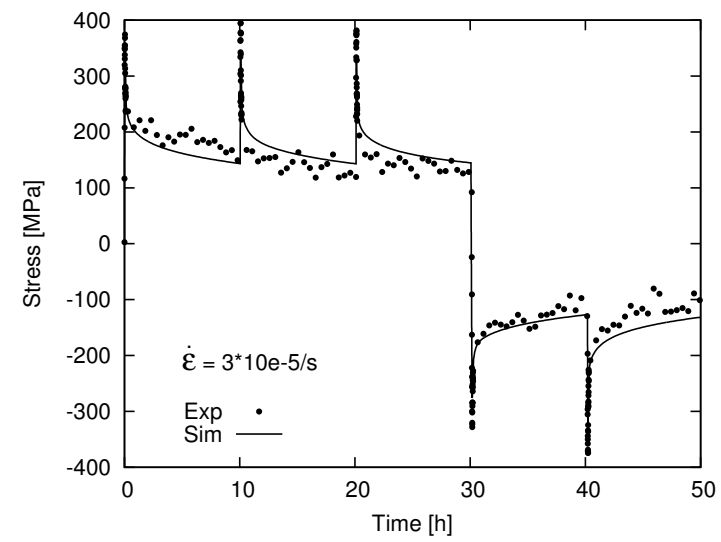

Figure 21. Simulation of a multiple relaxation test at $1050^{\circ} \mathrm{C}$ ( specimen orientation $=[111])$.

Examples of computed and experimental creep curves at $1050^{\circ} \mathrm{C}$ are shown in Figures 22 and 23. The evolution of the creep rate is reasonably well described for high stress levels. However, for low stress levels, the sharp increase of the creep rate is underestimated by the model. In Figure 23 the experimental creep curves show that the extent of secondary creep increases as the stress becomes lower, i.e. the onset of creep acceleration is delayed for lower stresses. In turn, creep acceleration becomes steeper at lower stresses. This behaviour is consistent with the observations reported for $950^{\circ} \mathrm{C}$ in [6]. The model however does not show this effect. Actually, the Orowan stress $\tau^{\text {Orowan }}$ shows the opposite dependency from the applied stress (see Figure 24): the drop of $\tau^{\text {Orowan }}$ accelerates (in terms of the corresponding creep strain) for lower stresses.

Because the dependences of the decrease of $\tau^{\text {Orowan }}$ and of the onset of creep acceleration on the stress level are opposed, channel widening cannot be the only reason for creep acceleration. An additional mechanism must contribute to tertiary creep in the case of low stresses and long test durations, which is not included in the present model version.

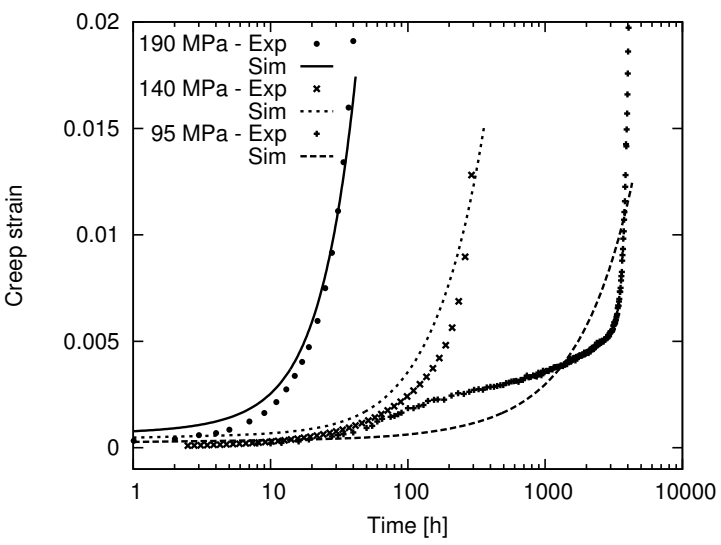

Figure 22. Creep curves at $1050^{\circ} \mathrm{C}($ specimen orientation $=$ [001]).

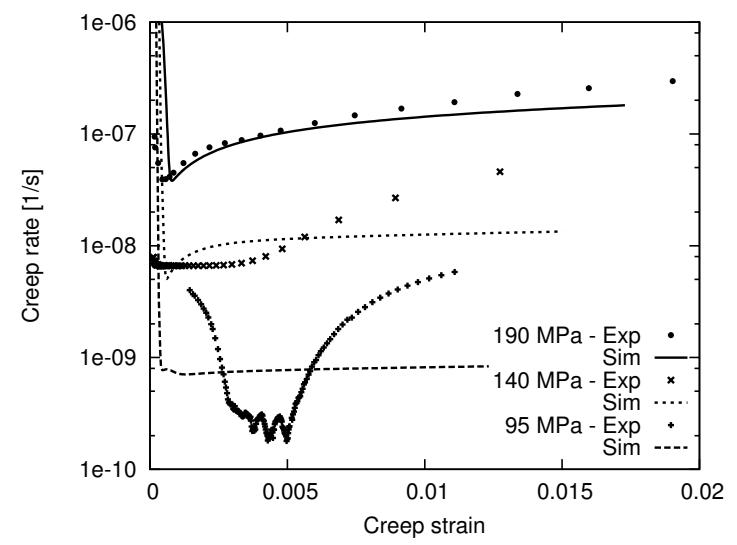

Figure 23. Creep rate at $1050^{\circ} \mathrm{C}($ specimen orientation $=[001])$.

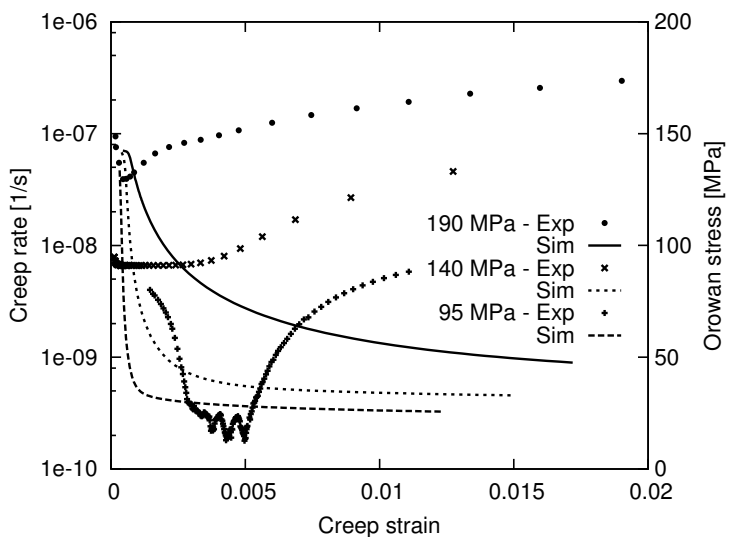

Figure 24. Creep rate at $1050^{\circ} \mathrm{C}$ versus Orowan stress (specimen orientation $=[001])$

In $<111>$ specimens, the model also does not describe the early increase of the creep rate that takes place at strain levels well below $0.5 \%$ (see Figure 25). Indeed, in this orientation the three channel types are equivalent and the morphology induced by creep is different than that observed in $<001>$ specimens.

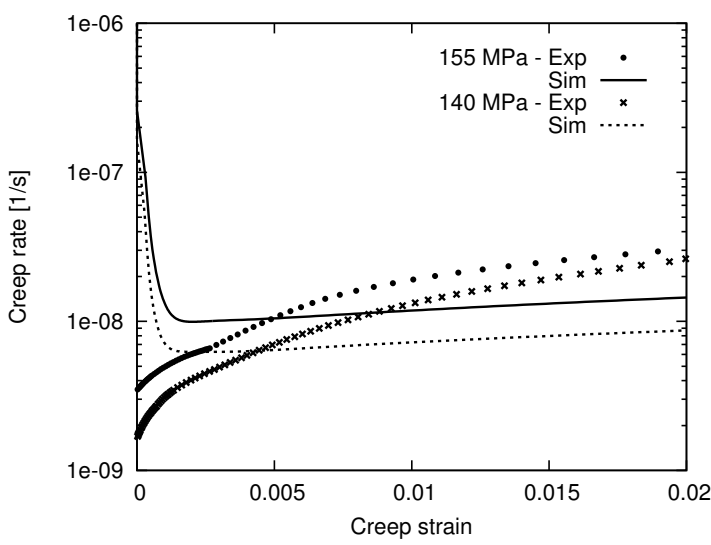

Figure 25 . Creep curves at $1050^{\circ} \mathrm{C}($ specimen orientation $=$ $<111>$ ). 
Figures 26 and 27 show the comparisons between the measured channel widths and the model results. The results are presented for the two FW specimens tested at $1050^{\circ} \mathrm{C}$ (see Table I). As a general rule, the scatter of the measurements is maximal around rafting completion $(w \approx 0.15 \mu \mathrm{m})$ and decreases afterwards. All in all, the model satisfyingly represents the time and stress dependence of the channel width evolution.

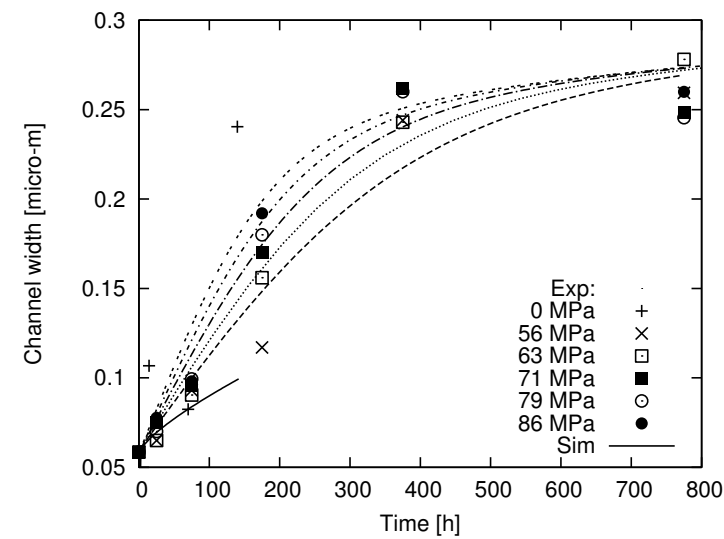

Figure 26. Evolution of channel width during creep tests at $1050^{\circ} \mathrm{C}$ (low stress specimen).

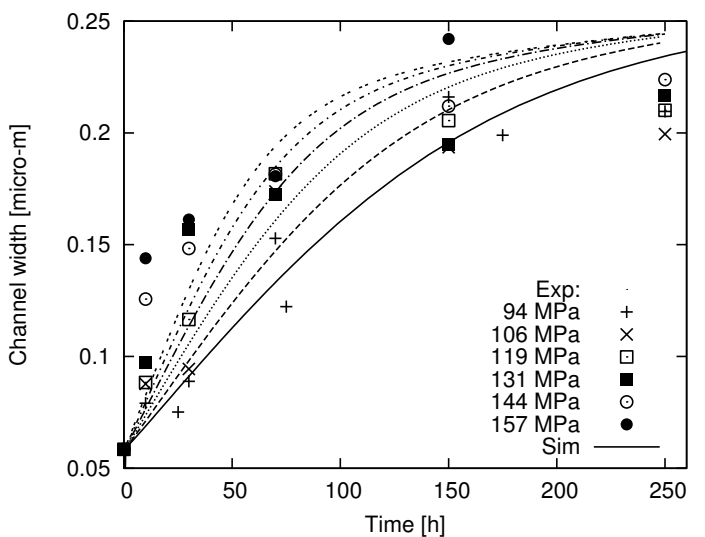

Figure 27. Evolution of channel width during creep tests at $1050^{\circ} \mathrm{C}$ (high stress specimen).

\section{Validation tests}

Non [001] uniaxial creep. Specimens with orientations between [001] and [011], $\left(0^{\circ} \leq \theta \leq 45^{\circ}, \rho=0^{\circ}\right)$, have been tested for creep at $950^{\circ} \mathrm{C}$ under $240 \mathrm{MPa}$ up to a strain of about $0.4 \%$. The SEM investigations have shown that the microstructure of the crept specimens is rafted, with a $\gamma$-channel width of about 0.14 $0.16 \mu \mathrm{m}$. This agrees with the model predictions (Table II), which also indicate pronounced channel widening but no essential difference between the degradation kinetics for [001] and [011] specimens.
Table II. Channel widths in specimens between [001] and [011] after creep at $950^{\circ} \mathrm{C}$ and $240 \mathrm{MPa}$.

\begin{tabular}{|c|c|c|c|c|}
\hline$\theta$ & $0^{\circ}$ & $15^{\circ}$ & $30^{\circ}$ & $45^{\circ}$ \\
\hline $\begin{array}{c}\text { Creep time }[\mathrm{h}] \\
\begin{array}{c}w \text { SEM } \\
\text { measurements }[\mu \mathrm{m}]\end{array}\end{array}$ & 331 & 307 & 528 & 529 \\
\hline$w$ Simulation $[\mu \mathrm{m}]$ & 0.15 & 0.15 & 0.15 & 0.14 \\
\hline
\end{tabular}

Non monotonous loading. To investigate the influence of loading/unloading sequences on channel widening, cyclic relaxation tests have been performed at $950^{\circ} \mathrm{C}$ with [001] specimens and different strain ratios $\left(R_{\varepsilon}=\varepsilon_{\min } / \varepsilon_{\max }\right)$ $R_{\varepsilon}=-1.33, \quad R_{\varepsilon}=-1.0, \quad R_{\varepsilon}=0.0$. The maximal strain $\varepsilon_{\max }=0.6 \%$ has been held for one hour per cycle and 200 cycles have been performed before SEM investigation. As predicted by the model, rafting is faster with increasing strain range (see Table III).

Table III. Channel widths after 200 cycles with dwell at $0.6 \%$ at $950^{\circ} \mathrm{C}$.

\begin{tabular}{|c|l|l|l|}
\hline Strain ratio $R_{\varepsilon}$ & -1.33 & -1.0 & 0.0 \\
\hline $\begin{array}{c}w \text { SEM } \\
\text { measurements }[\mu \mathrm{m}]\end{array}$ & 0.141 & 0.127 & 0.081 \\
\hline$w$ Simulation $[\mu \mathrm{m}]$ & 0.142 & 0.129 & 0.109 \\
\hline
\end{tabular}

Notched specimens. Two identical [001] cylindrically notched specimens have been tested at $950^{\circ} \mathrm{C}$ under a constant net stress of $180 \mathrm{MPa}, 700 \mathrm{~h}$, respectively $200 \mathrm{MPa}, 1000 \mathrm{~h}$ and investigated metallographically.

For the first specimen (700h, 180MPa), almost no rafting has been predicted along the specimen axis and at the notch corners, in agreement with the test. However, an intermediate state of rafting has been predicted at the notch root, which has not been observed in the test. Actually, the absence of any rafting progress at the notch root is surprising since uniaxial specimens with lower Von Mises stress levels already showed significant amount of rafting after $700 \mathrm{~h}$. This discrepancy is likely related to the large scatter usually observed in the initial stages of rafting.

For the second specimen $(1000 \mathrm{~h}, 200 \mathrm{MPa})$ a good qualitative agreement is obtained in all regions (see Figure 28). 


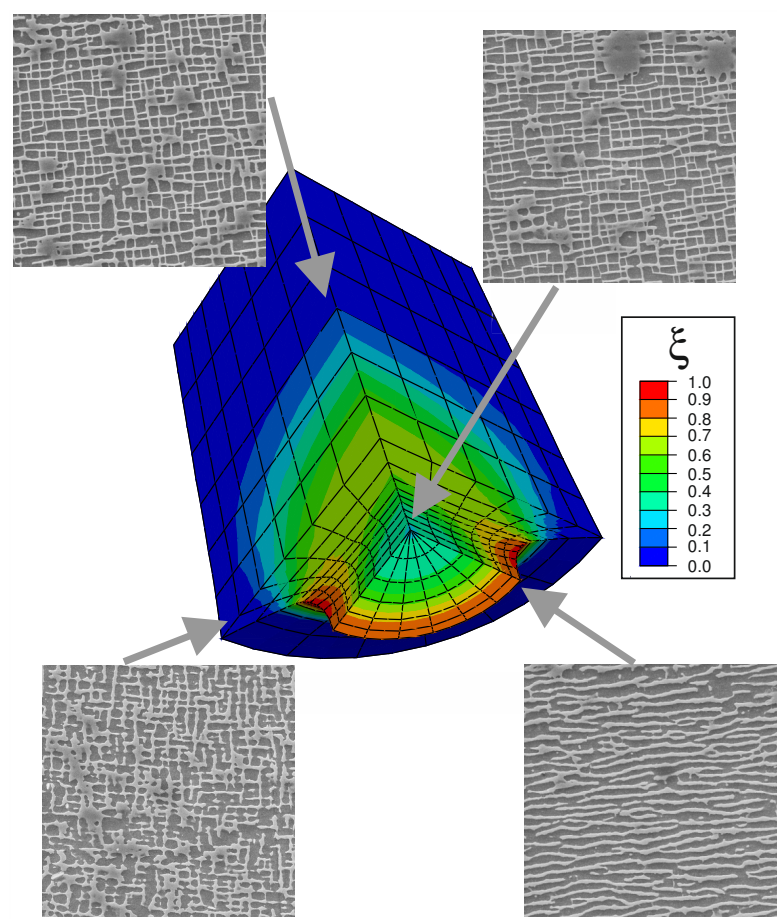

Figure 28. Degree of rafting $\xi$ in the (1000h, 200MPa) notched specimen as compared with SEM micrographs.

\section{Acknowledgements}

Financial support of the German Research Foundation (DFG, projects PO 405/10-1, LI 494/4-1 and PO 405/10-2, LI 494/4-2) is highly appreciated.

The present work would not have been possible without the test data generated within several previous research projects at other institutions. More specifically, the authors would like to thank A. Scholz (IfW, Darmstadt), M. Nazmy (ALSTOM, Baden), M. Maldini (CNR, Milan), H. Andersson (KIMAB, Stockholm), U. Glatzel (University of Bayreuth), G. Eggeler (RUB, Bochum) and P. Lukáš (Academy of Sciences of Czech Republic, Brno) for providing part of the necessary test data for this project. Additional thanks are due to M. Nazmy for providing degraded specimens of CMSX-4.

\section{References}

1. S. H. Ai, V. Lupinc and G. Onofrio, "Influence of precipitate morphology on high temperature fatigue crack growth of a single crystal nickel base superalloy," Scripta Metall. Mater., 29 (1993), $1385-1390$

2. M. Ott and H. Mughrabi, "Dependence of the high-temperature low-cycle fatigue behaviour of the monocrystalline nickel-base superalloys CMSX-4 and CMSX-6 on the $\gamma / \gamma^{\prime}$-morphology," Mater. Sci. and Eng., A272 (1999), 24-30.

3. A. Epishin, T. Link, M. Nazmy, M. Staubli, H. Klingelhöffer and G. Nolze, "Microstructural degradation of CMSX-4: kinetics and effect on mechanical properties," Proc. of the $11^{\text {th }}$ Int. Symp.
“Superalloys 2008”, ed. R. C. Reed et al. (Warrendale, PA: TMS, 2008), 725-731

4. A. Epishin, T. Link, H. Klingelhöffer, B. Fedelich and P. D. Portella, "Creep damage of single-crystal nickel base superalloys: mechanisms and effect on low cycle fatigue," Materials at High Temperature, 27 (2010), 53-59.

5. A. Epishin, T. Link, H. Klingelhöffer, B. Fedelich, U. Brückner and P. D. Portella, "New technique for characterisation of microstructural degradation under creep: application to the nickelbase superalloy CMSC-4," Mat. Sci. and Eng. A510-511 (2009), 262-265.

6. B. Fedelich, G. Künecke, A Epishin, T. Link and P. Portella, "Constitutive modelling of creep degradation due to rafting in single crystal Ni-base superalloys," Mat. Sci. and Eng. A510-511, (2009), 273-277.

7. A. I. Epishin, T. Link, U. Brückner and B. Fedelich, "Residual Stresses in the Dendritic Structure of Single-Crystal Nickel-Based Superalloys," Phys. Metals and Metallogr. 100 (2005), 192-199.

8. T. Link and P. Portella, "Influence of dendritic inhomogeneity on creep behaviour of a single-crystal superalloy of the $3^{\text {rd }}$ generation" (interim and final reports DFG PO 405/4-1,2; LI 494/3-1,2; 2000-2003)

9. B. Roebuck, D. Cox and R. Reed, "The temperature dependence of $\gamma^{\prime}$ volume fraction in a Ni-based single crystal superalloy from resisitivity measurements," Scripta Materialia, 44 (2001), 917-921.

10. L. Méric, P. Poubanne and G. Cailletaud, "Single crystal modeling for structural calculations: part 1-model presentation," $J$. Eng. Mat. Tech., 113 (1991) 162-170.

11. B. Fedelich, "A microstructural model for the monotonic and the cyclic mechanical behavior of single crystals of superalloys at high temperatures," Int. J. Plast., 18 (2002), 1-49.

12. A. Vattré and B. Fedelich, "On the relationship between anisotropic yield strength and internal stresses in single crystal superalloys," Mechanics of Materials, 43 (2011), 930-951.

13. D. Bettge and W. Österle, "Cube slip" in near-[111] oriented specimens of a single-crystal nickel-base superalloy," Scripta Materialia, 40 (1999), 389-395.

14. B. Fedelich, G. Künecke and A. Epishin, "Modelling of rafting and its influence in Ni-base superalloys," Proc. of the $8^{\text {th }}$ Liege Conference "Materials for Advanced Power Engineering", ed. J. Lecomte-Beckers et al. (Forschungszentrum Jülich, 2006), 475-484. 